\title{
Pinna Model for Hearing Instrument Applications
}

Kammersgaard, Nikolaj Peter Iversen; Kvist, Søren Helstrup; Thaysen, Jesper; Jakobsen, Kaj Bjarne

Published in:

Proceedings of 2014 Loughborough Antennas and Propagation Conference

Link to article, DOI:

10.1109/lapc.2014.6996340

Publication date:

2014

Link back to DTU Orbit

Citation (APA):

Kammersgaard, N. P. I., Kvist, S. H., Thaysen, J., \& Jakobsen, K. B. (2014). Pinna Model for Hearing Instrument Applications. In Proceedings of 2014 Loughborough Antennas and Propagation Conference (pp. 141-143). IEEE. https://doi.org/10.1109/lapc.2014.6996340

\section{General rights}

Copyright and moral rights for the publications made accessible in the public portal are retained by the authors and/or other copyright owners and it is a condition of accessing publications that users recognise and abide by the legal requirements associated with these rights.

- Users may download and print one copy of any publication from the public portal for the purpose of private study or research.

- You may not further distribute the material or use it for any profit-making activity or commercial gain

- You may freely distribute the URL identifying the publication in the public portal

If you believe that this document breaches copyright please contact us providing details, and we will remove access to the work immediately and investigate your claim 


\title{
Pinna Model for Hearing Instrument Applications
}

\author{
Nikolaj P. I. Kammersgaard*†, Søren H. Kvist ${ }^{\dagger}$, Jesper Thaysen ${ }^{\dagger}$ and Kaj B. Jakobsen* \\ s110371@student.dtu.dk, skvist@gnresound.com, jthaysen@gnresound.com, kbj@elektro.dtu.dk
}

*Department of Electrical Engineering, Electromagnetic Systems, Technical University of Denmark, Ørsteds Plads, Building 348, DK-2800 Kgs. Lyngby, Denmark

${ }^{\dagger}$ GN ReSound A/S, Lautrupbjerg 7, DK-2750 Ballerup, Denmark

\begin{abstract}
A novel model of the pinna (outer ear) is presented. This is to increase the understanding of the effect of the pinna on the on-body radiation pattern of an antenna placed inside the ear. Simulations of the model and of a realistically shaped ear are compared to validate the model. The radiation patterns, including the phase and gain, and the radiation efficiency are compared.
\end{abstract}

\section{INTRODUCTION}

Body-centric wireless communication has in recent years been the focus of attention for a lot of research. One of the main motivations is the commercial interest for wireless systems in body-worn devices. Particularly, it is of special interest to the hearing instrument (HI) manufacturers to investigate the possibility of Ear-to-Ear (E2E) communication. This area has been discussed in [1]-[4].

\section{THEORY}

The possibility of modeling the pinna as a dielectric slab is discussed in [1], but the effect of the pinna seems to have been accounted for twice. First from the simulated far-field radiation pattern and then from the model. The effect of a dielectric slab on a perpendicular incident plane wave obtained from [5] is given in Eq. 1 and 2 for the transmission and reflection coefficient:

$$
\begin{aligned}
T_{\text {pinna }} & =\frac{T_{1} T_{2} e^{-\gamma l}}{1+\Gamma_{1} \Gamma_{2} e^{-2 \gamma l}} \\
\Gamma_{\text {pinna }} & =\frac{\Gamma_{1}+\Gamma_{2} e^{-2 \gamma l}}{1+\Gamma_{1} \Gamma_{2} e^{-2 \gamma l}}
\end{aligned}
$$

where $T_{1}$ and $T_{2}$ are the transmission coefficients for the air-pinna and pinna-air interface, respectively, $\Gamma_{1}$ and $\Gamma_{2}$ are the reflection coefficients for the air-pinna and pinna-air interface, respectively, $\gamma$ is the propagation constant of the lossy dielectric, and $l$ is the thickness of the dielectric slab. The transmission and reflection coefficient for different thicknesses of the dielectric slab are plotted in Fig. 1 for a lossy dielectric with a relative permittivity of $\epsilon_{r}=50$ and a loss tangent of $\tan \delta=0.5$.

The on-body radiation pattern will be used to evaluate the radiation pattern. This is taken from [3] where it is used to calculate E2E path gain, based on multiple elliptical paths in a similar manner as in [1]. In [3] the phase is not taken into

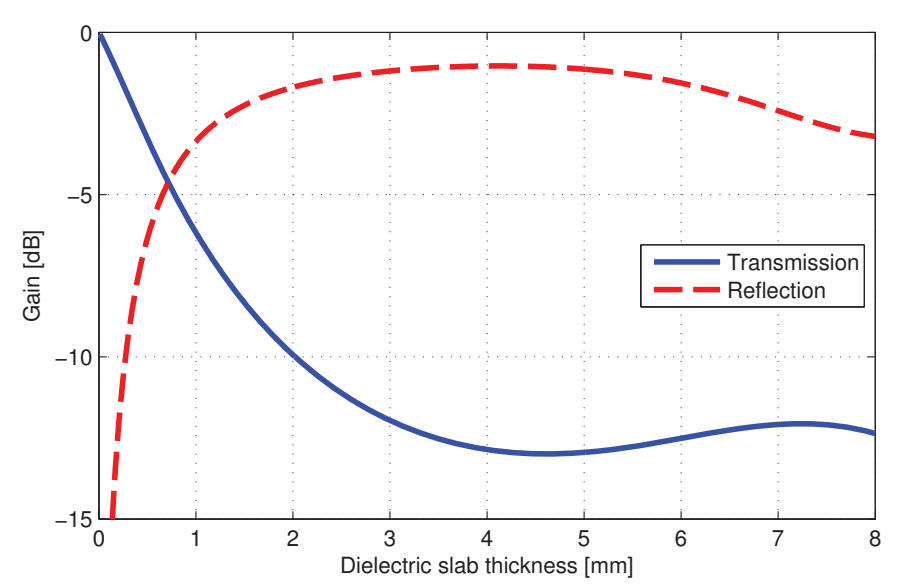

(a)

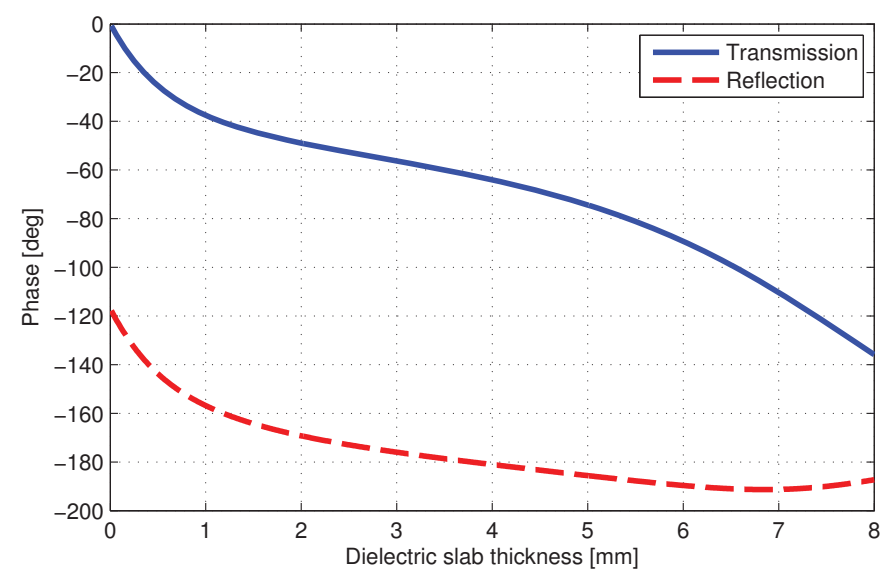

(b)

Fig. 1. Dielectric slab effect on a plane wave. Gain (a) and phase (b) of the plane wave reflection and transmission coefficient.

account, but here the phase of the electric field will be taken into account with the gain as given by Eq. 3:

$$
G_{\text {on-body }}(\phi)=\int_{0}^{\pi} G_{\theta}(\theta, \phi) e^{j \angle E_{\theta}(\theta, \phi)} \sin \theta d \theta .
$$

The resulting $G_{\text {on-body }}(\phi)$ will have both a magnitude or "gain" and a phase. Since the on-body gain directly influences the E2E path gain, it is important to understand how the onbody gain is changed by the presence of the ear. A simple model of the pinna has been developed for this purpose. 


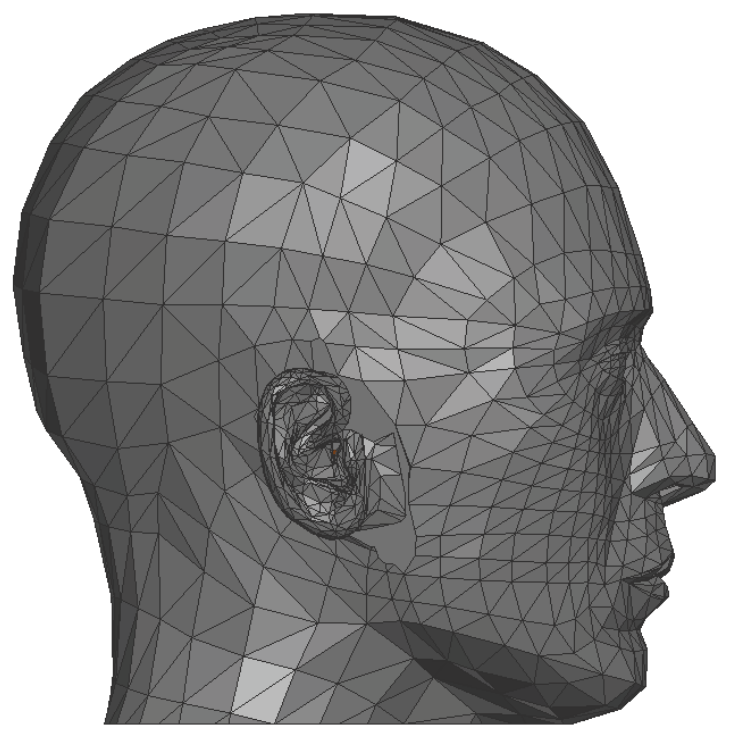

(a)

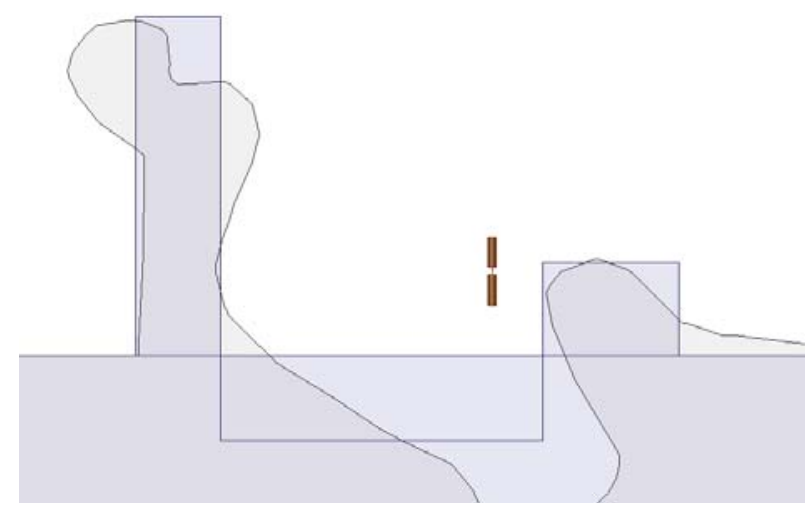

(c)

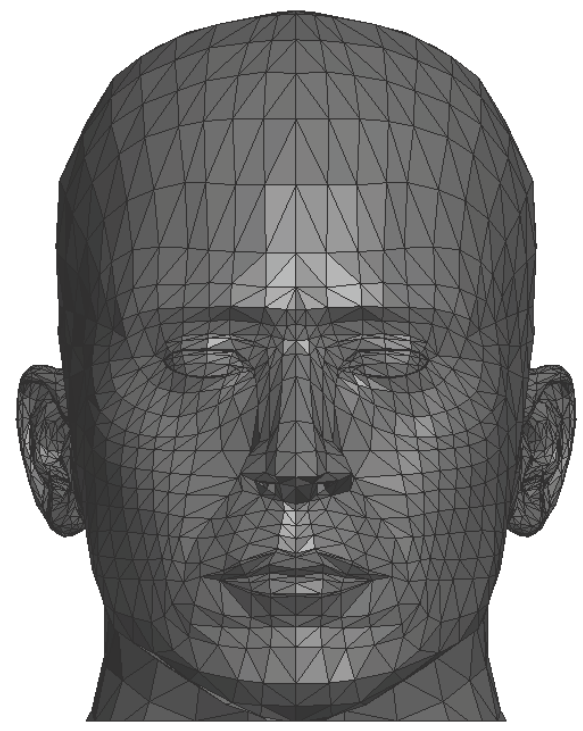

(b)

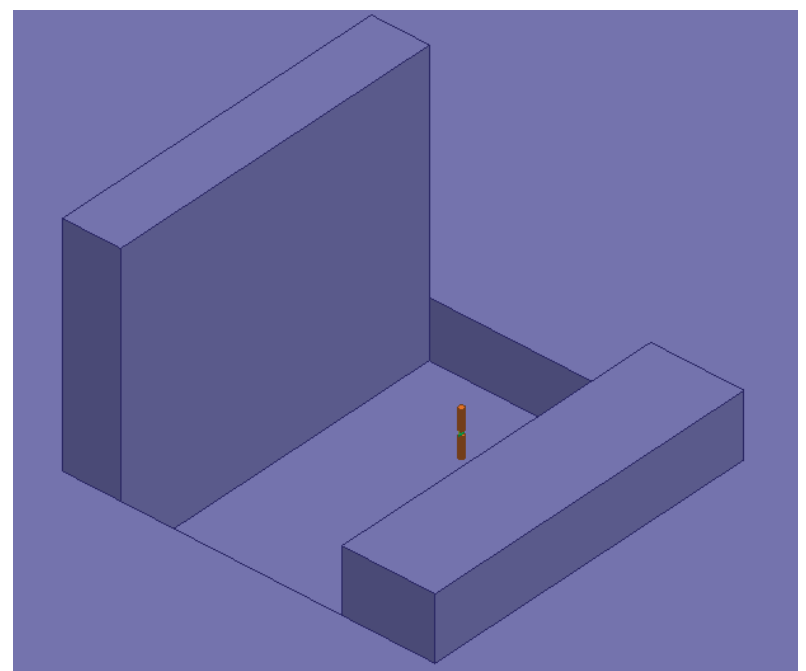

(d)

Fig. 2. The ear models. SAM head phantom with added ears used for real ear simulations, side view (a) and front view (b). The simple ear model, cut from side (c) and 3D view (d).

For the simulation the $\mathrm{z}$-axis is oriented perpendicular to the surface of the head and the $\mathrm{x}$-axis points in the upwards direction.

\section{Simulations}

To investigate the effect of the pinna, simulations in Ansoft HFSS v. 15.0 were done on the so called specific anthropomorphic mannequin (SAM) head. The head was given ears with an ear canal to model a realistic head. The ear models used were obtained from GN ReSound A/S. The company uses a number of ears for simulations and measurements for acoustic and electromagnetic purposes. Every human has a different head and ears. To limit the simulations and calculations, only a specific head and ears were tested. In Fig. $2 b$ and $2 a$ the head can be seen. A short PEC dipole with a length of $4 \mathrm{~mm}$ and diameter of $0.5 \mathrm{~mm}$ was chosen to mimic a point source. The simulations were done at $2.45 \mathrm{GHz}$. The dipole was oriented perpendicular to the surface of the head since this is most effective [4]. In free space the antenna has an omnidirectional on-body gain of $3 \mathrm{~dB}$ with $0^{\circ}$ phase change. The antenna center is located $5 \mathrm{~mm}$ above the surface of the head. The simulation results can be seen in Fig. 3. The thickness of the ear used is around $4.5 \mathrm{~mm}$ where it is thinnest. From Fig. 1 the expected gain loss and phase change from a dielectric slab of $4.5 \mathrm{~mm}$ thickness would be $13 \mathrm{~dB}$ and $-85^{\circ}$. The phase almost matches the simulation, but the gain is higher in the simulation. It is seen that the gain in the forward direction $\left(\phi=-90^{\circ}\right)$ is low. 


\section{MODEL AND COMPARISON}

From the results of the initial simulations a new model is suggested. It models the pinna and the trague, i.e., the small piece of cartilage in front of the ear canal, as two small dielectric slabs. Besides that a rectangular hole is added to model the concha, the largest and deepest concavity of the pinna. The model can be seen in Fig. 2c and 2d. In Fig. 3 the on-body gain and phase from HFSS simulations of the model can be seen and compared to the results of the real ear. The radiation efficiency of the simple model and the realistic ear is shown in Fig. 4. A very good correspondence between the simple model and the realistic ear simulations is seen.

The positive phase in the forward direction can be explained by reflections off the pinna. The wave propagates approximately $30 \mathrm{~mm}$, i.e., an electric length of $\sim 90^{\circ}$ and the reflection, as shown in Fig. $1 \mathrm{~b}$, results in a phase reversal of $\sim 180^{\circ}$-in total $\sim 90^{\circ}$. When the reflections add with the wave traveling directly from the antenna it results in a slightly positive phase. The phase in the backwards direction for the simple model is not quite as negative as for the realistic ear. This can be explained by the fact that some of the electromagnetic waves might creep around the pinna and from reflections off the trague. Different sizes of the pinna in the simple model was tested and it was observed that a large pinna would give a too high forward gain and a too little backwards gain. At the same time it would make the forward phase more positive and the backwards phase more negative. As the antenna is moved closer to the head the gain drops faster in the forward direction than in the backwards direction. This is observed in both the realistic ear and the simple model simulations.

The efficiency is seen to drop with around $2 \mathrm{~dB}$ per millimeter. Since both HIs would see this drop, the E2E path gain would decrease with around $4 \mathrm{~dB}$ per millimeter if the radiation pattern and polarization remain unchanged.

\section{Conclusion}

A simple model of the pinna was created to get a better understanding of the effect of the pinna on the far-field radiation of small $\mathrm{HI}$ antennas. The model consists of just two dielectric slabs and a rectangular hole. It is shown that a simple ear model can largely reproduce the effects of a more realistic ear model, in terms of the gain and phase of the far-field. The model reveals that significant reflections occur inside the ear, which contributes to the complex environment in which the $\mathrm{HI}$ antennas are located.

\section{REFERENCES}

[1] R. Chandra and A. J. Johansson, A Link Loss Model for the On Body Propagation Channel for Binaural Hearing Aids, in IEEE Trans. Antennas Propagat., vol. 61, no. 12, pp. 6180-6190, Dec. 2013.

[2] R. Chandra and A. J. Johansson, Miniaturized antennas for link between binaural hearing aids, in Proc. 32nd Annu. Int. Conf. of the IEEE Eng. in Med. and Biol. Soc., EMBC, pp. 688-691, Aug. 2010.

[3] S. H. Kvist, J. Thaysen and K. B. Jakobsen, Ear-to-Ear On-Body Channel Model for Hearing Aid Applications, submitted to IEEE Trans. Antennas Propagat., 2013.

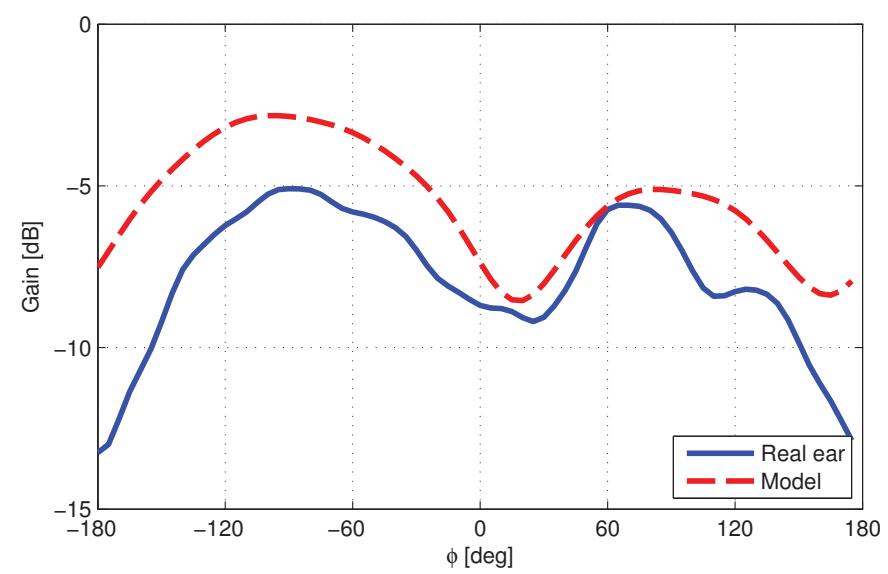

(a)

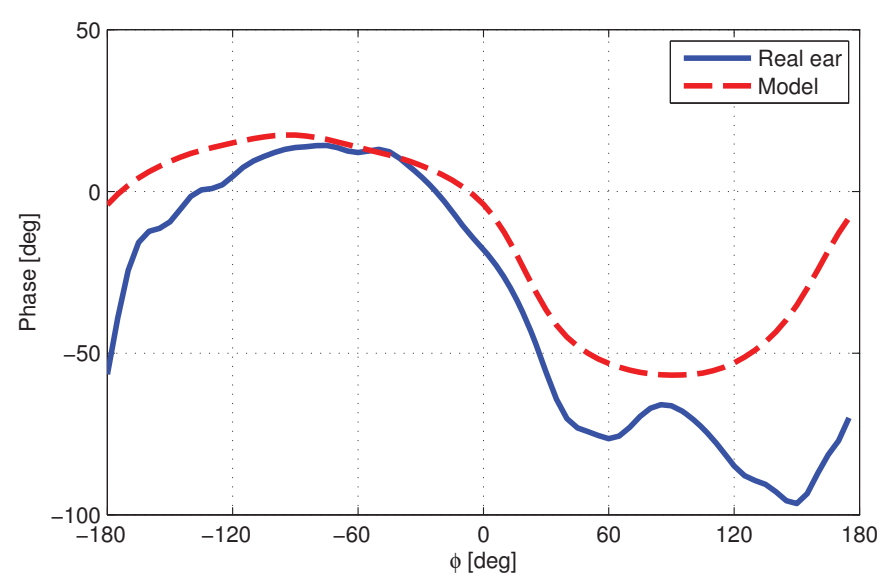

(b)

Fig. 3. Simulation results of on-body gain (a) and phase (b).

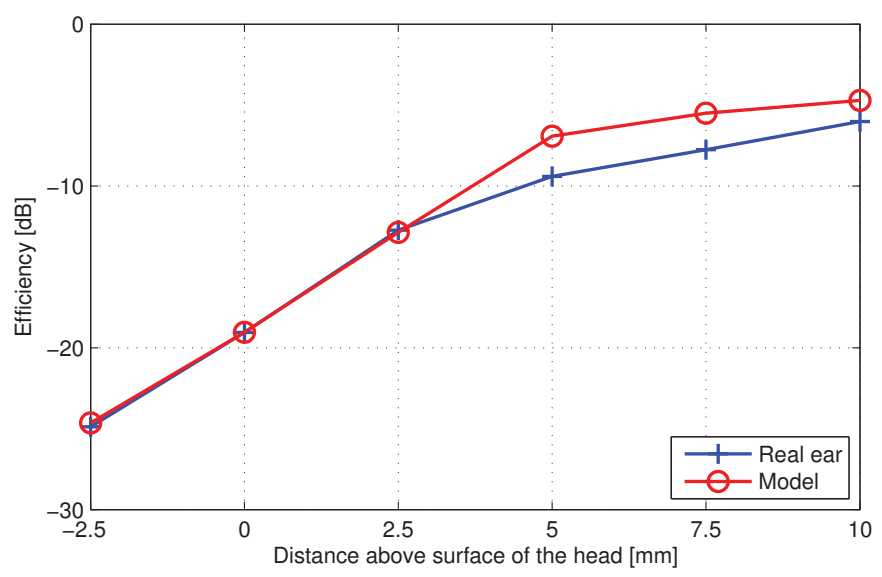

Fig. 4. Simulated radiation efficiency of model and real ear.

[4] S. H. Kvist, J. Thaysen and K. B. Jakobsen, Polarization of Unbalanced Antennas for Ear-to-Ear On-Body Communications at $2.45 \mathrm{GHz}$, in 2011 Loughborough Antennas and Propagation Conference (LAPC), Loughborough, UK, Oct. 2011.

[5] C. A. Balanis, Advanced Engineering Electromagnetics 2nd edition, Wiley, January 2012. 